\title{
KESTABILAN MODEL POPULASI MANGSA PEMANGSA DENGAN LAJU PEMANENAN TETAP
}

\author{
TRI HidAyati \\ Universitas PAMUlang \\ trihidayati1988@gmail.com
}

\begin{abstract}
Abstrak
Tujuan dari penelitian ini adalah mengkaji model populasi mangsa pemangsa dengan laju pemanenan tetap yang disebut dengan Model mangsa pemangsa Lotka Volterra dan menentukan kestabilan dari titik-titik keseimbangan. Penelitian ini menggunakan studi literatur yang artinya semua bahan dalam penelitian inii diambil, dikumpulkan dan disusun dari berbagai sumber buku yang telah ada. Adapun langkah-langkah dalam penelitian ini adalah mencari titik keseimbangan dari masing-masing persamaan, kemudian mengkaji perilaku dari setiap titik keseimbangan yang diperoleh. Pada penelitian ini dikaji secara analitis Model populasi mangsa pemangsa yang mempunyai tiga titik keseimbangan yaitu $E_{1}^{*}(0,0), E_{2}^{*}(K, 0)$, dan $E_{3}^{*}\left(\frac{c}{\beta}, \frac{r(\beta K-c)}{\alpha \beta K}\right)$. Kestabilan model populasi mangsa pemangsa dicapai pada titik keseimbangan $E_{3}^{*}\left(\frac{c}{\beta}, \frac{r(\beta K-c)}{\alpha \beta K}\right)$. Adapun adanya laju pemanenan tetap pada populasi mangsa pemangsa menyebabkan titik keseimbangan berubah, yaitu untuk memperoleh titik keseimbangan $x$ dengan mencari akar-akar dari polinomial $b \beta x^{3}-(r \beta+b c) x^{2}+\left(H_{x} \beta+H_{y} \alpha+r c\right) x-H_{x} c=0$, dengan $x>\frac{c}{\beta}$ dan untuk titik keseimbangan $y$ diperoleh dengan mensubstitusikan nilai $x$ yang diperoleh ke $y=\frac{H_{y}}{-c+\beta x}$.
\end{abstract}

Kata kunci: model populasi mangsa pemangsa, laju pemanenan tetap, kestabilan Sistem

\begin{abstract}
The aim of this research is to analyze predator- prey population model with constant rate of harvesting which is called The Lotka Volterra model of predator-prey and to determine the stability from equilibrium points. This research used literature study, it means that the resources for creating this research are taken, collected, and arranged from various existed research result and books. The procedural steps in this research namely looking for the equilibrium from each equation then analyzing the behavior of equilibrium points obtained. In this research, pre and predator population model was analyzed, that has equilibrium point $E_{1}^{*}(0,0), E_{2}^{*}(K, 0)$, and $E_{3}^{*}\left(\frac{c}{\beta}, \frac{r(\beta K-c)}{\alpha \beta K}\right)$. The equilibrium of predator-prey and was reached in equilibrium point $E_{3}^{*}\left(\frac{c}{\beta}, \frac{r(\beta K-c)}{\alpha \beta K}\right)$. The constant rate of harvesting in predator-prey population caused the equilibrium point had been changed, that was for obtaining the equilibrium point $\mathrm{x}$ by finding the roots of polynomial $b \beta x^{3}-(r \beta+b c) x^{2}+$ $\left(H_{x} \beta+H_{y} \alpha+r c\right) x-H_{x} c=0$, dengan $x>\frac{c}{\beta}$ with $x>\frac{c}{\beta}$ and for equilibrium point $\mathrm{y}$ is obtained by substitution $\mathrm{x}$ value that found to $y=\frac{H_{y}}{-c+\beta x}$.
\end{abstract}

Keywords: predator-prey population model, constant rate of harvesting, stability of system

\section{Pendahuluan}

Pertumbuhan suatu populasi dalam keadaan lingkungan tak terbatas merupakan peristiwa yang ideal dan tidak mungkin berlangsung sepanjang waktu, karena dalam keadaan yang sebenarnya daya dukung lingkungan dalam bentuk persediaan dan penyediaan sumberdaya seperti tempat hidup (berkembangbiak) dan makanan biasanya dalam 
keadaan terbatas. Populasi adalah sehimpunan individu atau kelompok individu suatu jenis makhluk hidup yang tergolong dalam satu spesies (atau kelompok lain yang dapat melangsungkan interaksi genetik dengan jenis yang bersangkutan), dan pada suatu wilayah tertentu menghuni suatu wilayah atau tata ruang tertentu Tarumingkeng, 1994. hal.10]. Di samping itu terdapat faktor-faktor yang berinteraksi di dalam populasi (pemangsa, persaingan makan, penyakit dan lain-lain) yaitu persaingan-persaingan antar individu dalam populasi, persaingan dengan populasi dari spesies yang sama, persaingan dengan populasi dari spesies yang lain (persaingan antar spesies) dan interaksi-interaksi lainnya dengan lingkungan populasi itu. Dalam predasi dikenal istilah pemangsa dan mangsa. Predator atau pemangsa adalah organisme yang memakan organisme lain untuk memenuhi kebutuhan hidup sehingga dapat mempertahankan hidupnya, sedang prey atau mangsa adalah organisme yang dijadikan mangsa oleh pemangsa. Sehingga mangsa menjadi pihak yang dirugikan. Laju pertumbuhan populasi tidak hanya dipengaruhi adanya pemangsaan maupun persaingan antara dua spesies atau lebih tetapi dapat juga dipengaruhi oleh faktor lain diantaranya adanya pemanenan dari populasi (mangsa pemangsa) tersebut. Adapun pemanenan adalah hasil akhir dari populasi yang sudah dipelihara selama waktu yang telah ditentukan Campbell and Reece, 2002.

Selain faktor-faktor di atas, masih ada faktor yang mempengaruhi laju pertumbuhan yakni pemanenan. Jika dalam populasi terjadi suatu pemanenan maka populasi tersebut bisa tetap berkembangbiak seperti biasa atau justru mengalami keadaan seimbang (kestabilan). Jika populasi mengalami kestabilan dalam pertumbuhan maka populasi tersebut, dalam hal ini, populasi mangsa dan pemangsa tidak mengalami pertumbuhan. Hal ini jelas dapat diketahui karena populasi mangsa pemangsa akan saling mempengaruhi dalam proses perkembangbiakan masing-masing spesies walaupun ada faktor pemanenan terhadap kedua spesies tersebut. Untuk mengetahui kestabilan dari suatu populasi, harus diketahui titik-titik keseimbangannya (equilibrium points). Titik keseimbangan dari sistem merupakan titik dimana sistem tersebut tidak mengalami perubahan sepanjang waktu. Jika titik $\left(x^{*}, y^{*}\right)$ adalah titik keseimbangan maka diselidiki pengaruh perubahan kecil pada titik keseimbangan tersebut. Jika titik $(x, y)$ merupakan titik di sekitar titik keseimbangan maka titik $(x, y)$ dapat dinyatakan sebagai

$$
(x, y)=\left(x^{*}+\triangle x, y^{*}+\triangle y\right)
$$

Karena $\left(x^{*}, y^{*}\right)$ adalah titik keseimbangan maka $f_{1}\left(x^{*}, y^{*}\right)=f_{2}\left(x^{*}, y^{*}\right)=\ldots=f_{x}\left(x^{*}, y^{*}\right)$. Oleh karena itu, diperoleh sistem linear

$$
\left.\begin{array}{rl}
\frac{d x_{1}}{d t} & =\frac{\partial f_{1}\left(x^{*}, y^{*}\right)}{\partial x} \Delta x+\frac{\partial f_{1}\left(x^{*}, y^{*}\right)}{\partial y} \Delta y \\
\frac{d x_{2}}{d t} & =\frac{\partial f_{2}\left(x^{*}, y^{*}\right)}{\partial x} \Delta x+\frac{\partial f_{2}\left(x^{*}, y^{*}\right)}{\partial y} \Delta y \\
\vdots & \\
\frac{d x_{n}}{d t} & =\frac{\partial f_{n}\left(x^{*}, y^{*}\right)}{\partial x} \Delta x+\frac{\partial f_{n}\left(x^{*}, y^{*}\right)}{\partial y} \Delta y .
\end{array}\right\}
$$

Sistem (2) dapat disajikan dalam bentuk matriks

$$
J(x)=\left(\begin{array}{r}
\Delta x_{1} \\
\Delta x_{2} \\
\vdots \\
\Delta x_{n}
\end{array}\right)
$$


Pada sistem dua persamaan diferensial maka matriks $J(x)$ menjadi :

$$
J(x)=\left(\begin{array}{ll}
\frac{\partial f_{1}}{\partial x_{1}} & \frac{\partial f_{1}}{\partial x_{2}} \\
\frac{\partial f_{2}}{\partial x_{1}} & \frac{\partial f_{2}}{\partial x_{2}}
\end{array}\right)
$$

Persamaan karakteristik dari matriks Jacobian $J$ adalah

$$
f(\lambda)=\lambda^{2}-T \lambda+\gamma=0
$$

Sedangkan akar karakteristiknya adalah

$$
\lambda_{1,2}=\frac{T \pm \sqrt{T^{2}-4 \gamma}}{2} .
$$

Definisi 1.1. Titik $\left(x_{1}^{*}, x_{2}^{*}, \ldots, x_{n}^{*}\right)$ disebut titik keseimbangan pada sistem (2) jika $f_{1}\left(x_{1}^{*}, x_{2}^{*}, \ldots, x_{n}^{*}\right)=0, f_{2}\left(x_{1}^{*}, x_{2}^{*}, \ldots, x_{n}^{*}\right)=0, \ldots, f_{n}\left(x_{1}^{*}, x_{2}^{*}, \ldots, x_{n}^{*}\right)=0$.

Bellomo and Preziosi, 1994

Berdasarkan Definisi 1.1 maka titik keseimbangan pada sistem dua persamaan diferensial akan dicapai pada saat $\frac{d x}{d t}=0$ dan $\frac{d y}{d t}=0$.

Selanjutnya untuk mengetahui perilaku sistem di sekitar titik keseimbangan digunakan konsep kestabilan. Sistem stabil asimtotik berarti pengaruh dari perubahan kecil cenderung menghilang sama sekali (tidak berpengaruh), sedangkan ketidakstabilan berarti suatu perubahan kecil pada syarat awalnya akan berakibat perubahan besar pada penyelesaian. Menurut Bellomo dan Presziosi, kriteria kestabilan dapat ditentukan dengan mencari nilai eigen atau akar karakteristik dari $\mathrm{J}(\mathrm{x})$ Bellomo and Preziosi, 1994. Sehingga perilaku dari titik keseimbangan dapat ditentukan dengan menemukan nilai-nilai eigen atau akar-akar karakteristik. Dengan demikian trayektori dapat digambarkan dan perilaku solusinya dapat dimengerti. Perilaku solusi berdasarkan nilai eigen atau akar karakteristik dapat dibagi menjadi beberapa kasus.

Kasus 1. Nilai-nilai eigennya real tak sama dan bertanda sama jika $\delta=\left(T^{2}-4 \gamma\right)>0$.

Diasumsikan bahwa $\lambda_{1}$ dan $\lambda_{2}$ berbeda dan real. Nilai eigennya semuanya negatif jika $T<0$ maka sistem tersebut stabil asimtotis tetapi jika semuanya positif $(T>0)$ maka sistem tersebut tidak stabil.

Kasus 2. Nilai-nilai eigennya real dan berbeda tanda.

Diasumsikan bahwa $\lambda_{1}$ dan $\lambda_{2}$ real dan berbeda tanda. Dalam hal ini akan disebut titik sadle. Semua trayektori akan menjauh ke tak hingga sehingga mengakibatkan bahwa titik saddle akan selalu tidak stabil.

Kasus 3. Nilai-nilai eigennya real dan sama (akar kembar) jika $\delta=\left(T^{2}-4 \gamma\right)=0$.

Diasumsikan bahwa $\lambda_{1}=\lambda_{2}$ dan nilainya real. Jika nilai eigennya semuanya negative $(T<0)$ maka sistem tersebut stabil asimtotis tetapi jika semuanya positif $(T>0)$ maka sistem tersebut tidak stabil.

Kasus 4. Nilai-nilai eigennya komplek jika $\delta=\left(T^{2}-4 \gamma\right)<0$.

Dalam kasus ini nilai eigennya komplek, yang dapat dinyatakan sebagai

$$
\lambda_{ \pm}=\beta \pm i \mu
$$

Ini akan menghasilkan perilaku yang disebut spiral dimana kestabilan ditentukan oleh tanda bagian real $\beta$. Untuk kasus $\beta<0$ (bagian real negatif), trayektori solusinya berbeda arah dan titik kritiknya stabil asimtotis. Tetapi jika $\beta>0$ (bagian real positif) maka titik kritiknya akan tidak stabil. 
Kasus 5. Nilai-nilai eigennya imajiner murni.

Dalam kasus ini nilai-nilai eigennya dapat dinyatakan sebagai

$$
\lambda_{ \pm}= \pm i \mu
$$

Dalam hal ini solusinya merupakan osilator dan akan stabil secara alamiah. Titik kritisnya disebut sebagai titik pusat (center point).

Waluya, 2006, hal.160-163]

\subsection{Model Populasi Mangsa Pemangsa}

Asumsi 1 : Misal $x$ menyatakan jumlah populasi mangsa dalam waktu t,y menyatakan jumlah populasi pemangsa dalam waktu $t$. Jika dalam suatu ekosistem tidak ada pemangsa maka populasi akan berkembang pesat. Keadaan ini dapat dinyatakan dalam bentuk persamaan diferensial sebagai berikut:

$$
\frac{d x}{d t}=r x-b x^{2}
$$

dengan $r, b>0$. Dengan menganggap mangsa hanya dimakan oleh satu pemangsa. Maka laju pertumbuhan mangsa akan menurun dalam jumlah yang proporsional sebagai akibat dari interaksi antara mangsa dan pemangsa sehingga persamaan (5) menjadi:

$$
\frac{d x}{d t}=r x-b x^{2}-\alpha x y .
$$

Asumsi 2 :Jika dalam ekosistem tidak ada mangsa maka populasi pemangsapun akan menurun karena pemangsa tidak memperoleh mangsa sebagai makanan sekaligus. Keadaan ini dapat dinyatakan dalam bentuk persamaan sebagai berikut:

$$
\frac{d y}{d t}=-c y,
$$

dengan $c>0$. Kehadiran mangsa pada laju pertumbuhan pemangsa akan mengakibatkan terjadinya penambahan jumlah populasi pemangsa karena pemangsa mendapatkan supply makanan. Oleh karena itu persamaan (7) menjadi:

$$
\frac{d y}{d t}=-c y+\beta x y \text {. }
$$

Dari persamaan (6) dan (8), diperoleh persamaan model populasi mangsa pemangsa (Persamaan Lotka Volterra) :

$$
\left.\begin{array}{l}
\frac{d x}{d t}=(r-b x-\alpha y) x \\
\frac{d y}{d t}=(-c+\beta x) y,
\end{array}\right\}
$$

dimana $r, b=\frac{r}{K}, c, \alpha, \beta$ merupakan konstanta postitf dengan $r$ adalah laju pertumbuhan intrinsik mangsa, $K$ adalah daya dukung, $\alpha$ adalah laju pemangsaan oleh pemangsa, $\beta$ adalah laju perkembangbiakan pemangsa akibat pemangsaan, dan $c$ adalah laju kematian pemangsa karena tidak ada mangsa. 


\subsection{Model Populasi Mangsa Pemangsa dengan Laju Pemanenan}

Jika dalam suatu ekosistem terdapat populasi (dalam hal ini mangsa dan pemangsa/ predator) yang sedang mengalami pertumbuhan maka dapat terjadi pemanenan terhadap salah satu populasi atau keduanya.

Asumsi 1: Misal $x$ menyatakan jumlah populasi mangsa dalam waktu $t, y$ menyatakan jumlah populasi pemangsa dalam waktu $t, H_{x}$ menyatakan jumlah pemanenan pada mangsa dalam waktu $t$ dan $H_{y}$ menyatakan jumlah pemanenan pada pemangsa dalam waktu $t$. Jika dalam suatu ekosistem tidak ada pemangsa dan tidak terjadi pemanenan maka populasi akan berkembang pesat. Keadaan ini dapat dinyatakan dalam bentuk persamaan diferensial sebagai berikut:

$$
\frac{d x}{d t}=r x-b x^{2}
$$

dengan $r, b>0$. Dengan menganggap mangsa hanya dimakan oleh satu pemangsa dan terjadi pemanenan dengan laju tetap. Maka laju pertumbuhan mangsa akan menurun dalam jumlah yang proporsional sebagai akibat dari interaksi antara mangsa dan pemangsa serta terjadinya pemanenan dengan laju tetap sehingga persamaan 10 menjadi:

$$
\frac{d x}{d t}=r x-b x^{2}-\alpha x y-H_{x} .
$$

Asumsi 2 : Jika dalam ekosistem tidak ada mangsa dan terjadi pemanenan maka populasi pemangsapun akan menurun karena pemangsa tidak memperoleh mangsa sebagai makanan sekaligus terjadinya pemanenan secara tetap pada populasi pemangsa. Keadaan ini dapat dinyatakan dalam bentuk persamaan sebagai berikut:

$$
\frac{d y}{d t}=-c y-H_{y}
$$

dengan $c, H_{y}>0$. Kehadiran mangsa pada laju pertumbuhan pemangsa akan mengakibatkan terjadinya penambahan jumlah populasi pemangsa karena pemangsa mendapatkan supply makanan. Oleh karena itu persamaan 12 menjadi:

$$
\frac{d y}{d t}=-c y-H_{y}+\beta x y .
$$

Dari persamaan (11) dan (13), diperoleh persamaan model populasi mangsa pemangsa dengan laju pemanenan tetap (Persamaan Lotka Volterra) :

$$
\left.\begin{array}{l}
\frac{d x}{d t}=(r-b x-\alpha y) x-H_{x} \\
\frac{d y}{d t}=(-c+\beta x) y-H_{y},
\end{array}\right\}
$$

dengan $r$ adalah laju pertumbuhan intrinsik mangsa, $K$ adalah daya dukung, $\alpha$ adalah laju pemangsaan oleh pemangsa, $\beta$ adalah laju perkembangbiakan pemangsa akibat pemangsaan, $c$ adalah laju kematian pemangsa karena tidak ada mangsa, $H_{x}$ adalah laju pemanenan mangsa, dan $H_{y}$ adalah laju pemanenan pemangsa.

\section{Metode Penelitian}

Penelitian ini menggunakan studi literatur, artinya semua bahan dalam penyusunan penelitian ini diambil, dikumpulkan, dan disusun dari berbagai sumber buku yang telah ada. Adapun materi yang digunakan antara lain persamaan diferensial, sistem persamaan 
diferensial, keseimbangan dan kestabilan, linearisasi sistem, model populasi mangsa pemangsa, serta pemanenan. Langkah-langkah yang ditempuh dalam penelitian ini sebagai berikut :

1. Untuk populasi mangsa pemangsa

a. Mencari titik keseimbangan (equilibrium points) dari sistem model pertumbuhan populasi mangsa pemangsa.

b. Linearisasi sistem persamaan diferensial nonlinear.

c. Menganalisa kestabilan dari sistem model pertumbuhan populasi mangsa pemangsa.

2. Untuk populasi mangsa pemangsa dengan laju pemanenan tetap

a. Mencari titik keseimbangan (equilibrium points) dari sistem model pertumbuhan populasi mangsa pemangsa dengan laju pemanenan tetap.

b. Linearisasi sistem persamaan diferensial nonlinear.

c. Menganalisa kestabilan dari sistem model pertumbuhan populasi mangsa pemangsa dengan laju pemanenan tetap untuk setiap titik keseimbangan yang diperoleh.

3. Menarik kesimpulan

\section{Hasil dan Pembahasan}

\subsection{Kestabilan Model Populasi Mangsa Pemangsa}

Berdasarkan persamaan Lotka Volterra, populasi mangsa dan pemangsa akan terjadi titik keseimbangan yang merupakan titik di mana jumlah mangsa dan pemangsa berada dalam keadaan seimbang atau tidak mengalami diperoleh tiga titik keseimbangan, yaitu:

$$
E_{1}(0,0), E_{2}(K, 0), \operatorname{dan} E_{3}\left(\frac{c}{\beta}, \frac{r(\beta K-c)}{\alpha \beta K}\right) .
$$

Matriks Jacobian dari sistem persamaan tersebut adalah

$$
\begin{aligned}
J_{(\bar{x}, \bar{y})}=\left(\begin{array}{cc}
\frac{\partial f_{1}}{\partial x_{1}} & \frac{\partial f_{1}}{\partial x_{2}} \\
\frac{\partial f_{2}}{\partial x_{1}} & \frac{\partial f_{2}}{\partial x_{2}}
\end{array}\right)_{(\bar{x}, \bar{y})}=\left(\begin{array}{cc}
k_{11} & k_{12} \\
k_{21} & k_{22}
\end{array}\right) \\
f_{1}(x, y)=r x\left(1-\frac{x}{K}\right)-\alpha y x \\
=r x-\frac{r x^{2}}{K}-\alpha y x . \\
f_{2}(x, y)=-c y+\beta x y .
\end{aligned}
$$

Jadi matriks Jacobian untuk titik keseimbangan $(\bar{x}, \bar{y})$ adalah sebagai berikut:

a. Untuk titik keseimbangan $(0,0)$

$$
J_{(0,0)}=\left(\begin{array}{rr}
r & 0 \\
0 & -c
\end{array}\right)
$$


b. Untuk titik keseimbangan $(K, 0)$

$$
J_{(0,0)}=\left(\begin{array}{cc}
-r & -\alpha K \\
0 & -c+\beta K
\end{array}\right)
$$

c. Untuk titik keseimbangan $\left(\frac{c}{\beta}, \frac{r(\beta K-c)}{\alpha \beta K}\right)$

$$
J_{(0,0)}=\left(\begin{array}{cc}
-\frac{r c}{\beta K} & -\frac{\alpha c}{\beta} \\
\frac{r(\beta K-c)}{\alpha K} & 0
\end{array}\right)
$$

\subsection{Analisa Titik Keseimbangan}

1. Untuk titik keseimbangan $E_{1}(0,0)$

Trace untuk matriks $J_{(0,0)}=r-c$, dan determinan untuk $J_{(0,0)}=-r c$. Maka persamaan karakteristik dari matriks Jacobian di atas adalah

$$
f(\lambda)=\lambda^{2}-(r-c) \lambda-r c=0,
$$

dan akan diperoleh akar-akar karakteristik sebagai berikut:

$$
\lambda_{1}=r \operatorname{dan} \lambda_{2}=-c .
$$

Karena $\lambda_{1}>0$ dan $\lambda_{2}<0$ maka maka titik keseimbangan $E_{1}(0,0)$ adalah titik pelana (saddle point) yang cenderung tidak stabil.

2. Untuk titik keseimbangan $E_{2}(K, 0)$

Trace untuk matriks $J_{(0,0)}=-r-c+\beta K$, dan determinan untuk $J_{(0,0)}=r c-r \beta K$. Maka persamaan karakteristik dari matriks Jacobian di atas adalah

$$
f(\lambda)=\lambda^{2}-(-r-c+\beta K) \lambda+r c-r \beta K=0,
$$

dan akan diperoleh akar-akar karakteristik sebagai berikut:

$$
\lambda_{1}=-r \operatorname{dan} \lambda_{2}=\beta K-c .
$$

Karena $\lambda_{1}<0$ dan $\lambda_{2}<0$ maka maka titik keseimbangan $E_{2}(K, 0)$ adalah titik pelana (saddle point) yang cenderung tidak stabil.

3. Untuk titik kseimbangan $E_{3}\left(\frac{c}{\beta}, \frac{r(\beta K-c)}{\alpha \beta K}\right)$

Trace untuk matriks $J_{(0,0)}=-\frac{r c}{\beta K}$, dan determinan untuk $J_{(0,0)}=\frac{c r}{\beta K}(\beta K-c)$. Maka persamaan karakteristik dari matriks Jacobian di atas adalah

$$
f(\lambda)=\lambda^{2}+\frac{r c}{\beta K} \lambda+\frac{c r}{\beta K}(\beta K-c)=0,
$$

dan akan diperoleh akar-akar karakteristik sebagai berikut:

$$
\lambda_{1,2}=\frac{-\frac{c r}{\beta K} \pm \sqrt{\frac{c^{2} r^{2}}{\beta^{2} K^{2}}-4 c r+4 \frac{c^{2} r}{\beta K}}}{2} .
$$

Persamaan karakteristik di atas mempunyai akar-akar karakteristik real dan keduanya bertanda negatif. Dengan demikian titik keseimbangan $E_{3}\left(\frac{c}{\beta}, \frac{r(\beta K-c)}{\alpha \beta K}\right)$ adalah stabil 
asimtotis.

\subsection{Kestabilan Model Populasi Mangsa Pemangsa Dengan Laju Pemanenan Tetap}

Pada bagian sebelumnya telah dijelaskan tentang model populasi mangsa pemangsa dan telah diketahui juga titik-titik keseimbangannya beserta perilaku (kestabilan) dari masing-masing titik keseimbangan yang diperoleh. Persamaan model populasi mangsa pemangsa dengan laju pemanenan tetap seperti pada persamaan (14).

Dari persamaan (14) diketahui bahwa $H_{x}$ adalah laju pemanenan tetap untuk populasi mangsa dan $H_{y}$ adalah laju pemanenan tetap untuk populasi pemangsa yang keduanya bernilai positif. Untuk mendapatkan titik keseimbangan maka $\frac{d x}{d t}=0$ dan $\frac{d y}{d t}=0$. Dengan memperhatikan syarat terjadinya titik keseimbangan tersebut maka diperoleh persamaan

1. Untuk $\frac{d x}{d t}=0$ maka

$$
y=\frac{-b x^{2}+r x-H_{x}}{\alpha x} .
$$

Persamaan (15) adalah suatu dari persamaan kuadrat. Agar didapatkan titik keseimbangan $(x, y)$ yang berada pada kuadran I maka diskriminan persamaan 15 harus bernilai positif $(D>0)$.

2. Untuk $\frac{d y}{d t}=0$ maka

$$
y=\frac{H_{y}}{-c+\beta x} .
$$

Karena diketahui $H_{y}$ adalah laju pemanenan tetap untuk populasi pemangsa dan bernilai positif, maka dari persamaan (16) diperoleh $H_{y}>0 \rightarrow y>0$ dan $-c+\beta x>0$ dimana $\beta_{x}>c$ maka $x>\frac{c}{\beta}$.

Karena $\frac{d x}{d t}=0$ dan $\frac{d y}{d t}=0$ maka $\frac{d x}{d t}=\frac{d y}{d t}$

$$
\Leftrightarrow-b x^{2}+r x+\alpha x y-\beta x y+c y-H_{x}+H_{y}=0
$$

Persamaan (15) disubstitusikan ke persamaan (17) sebagai berikut:

$$
b \beta x^{3}-(r \beta+b c) x^{2}+\left(H_{x} \beta+H_{y} \alpha+r c\right) x-H_{x} c=0,
$$

dengan $x>\frac{c}{\beta}$.

Untuk analisa kestabilan dari titik-titik keseimbangan yang diperoleh dengan menggunakan matriks Jacobian. Matriks Jacobian dari sistem persamaan (18) adalah:

$$
J_{(\bar{x}, \bar{y})}=\left(\begin{array}{rr}
r-2 b x-\alpha y & -\alpha x \\
\beta y & -c+\beta x
\end{array}\right)
$$


Persamaan karakteristik dari matriks Jacobian di atas adalah:

$$
\begin{aligned}
\left|\begin{array}{rr}
P-\lambda & -Q \\
R & S-\lambda
\end{array}\right| & =0 \\
& \Leftrightarrow(P-\lambda)(S-\lambda)-R(-Q)=0 \\
& \Leftrightarrow \lambda^{2}-(P+S) \lambda+(P S+R Q)=0 .
\end{aligned}
$$

Jadi persamaan karakteristiknya adalah $g(\lambda)=\lambda^{2}-(P+S) \lambda+(P S+R Q)=0$, dimana $P=r-2 b x-\alpha y, Q=\alpha x, R=\beta y$, dan $S=-c+\beta x$.

\section{Simpulan}

Berdasarkan hasil pembahasan maka dapat diambil kesimpulan sebagai berikut:

1. Model populasi mangsa pemangsa (model Lotka Volterra) mempunyai tiga titik keseimbangan yaitu $E_{1}^{*}(0,0), E_{2}^{*}(K, 0)$, and $E_{3}^{*}\left(\frac{c}{\beta}, \frac{r(\beta K-c)}{\alpha \beta K}\right)$.

2. Kestabilan model populasi mangsa pemangsa terjadi pada titik keseimbangan

$$
E_{3}^{*}\left(\frac{c}{\beta}, \frac{r(\beta K-c)}{\alpha \beta K}\right)
$$

3. Adapun adanya pemanenan tetap pada populasi mangsa pemangsa menyebabkan titik keseimbangan berubah, yaitu untuk titik keseimbangan $\mathrm{x}$ dengan mencari akarakar dari polinomial $b \beta x^{3}-(r \beta+b c) x^{2}+\left(H_{x} \beta+H_{y} \alpha+r c\right) x-H_{x} c=0$, dengan $x>\frac{c}{\beta}$ dan untuk titik keseimbangan $y$ diperoleh dengan mensubstitusikan nilai $x$ yang diperoleh ke $y=\frac{H_{y}}{-c+\beta x}$.

Dalam penelitian ini hanya membahas tentang kestabilanmodel populasi mangsa pemangsa serta kestabilan model populasi mangsa pemangsa dengan laju pemanenan tetap. Bagi yang tertarik untuk melanjutkan penelitian ini maka dapat meneliti model populasi mangsa pemangsa dengan memperhatikan faktor tundaan waktu atau laju pemanenan yang tidak tetap.

\section{Referensi}

[Bellomo and Preziosi, 1994] Bellomo, N. and Preziosi, L. (1994). Modelling mathematical methods and scientific computation, volume 1. CRC press.

[Campbell and Reece, 2002] Campbell, R. and Reece, L. (2002). Mitchell. 2004, volume 3. Erlangga, Jakarta.

[Tarumingkeng, 1994] Tarumingkeng, R. C. (1994). Dinamika populasi: kajian ekologie kuantitatif. Pustaka Sinar Harapan.

[Waluya, 2006] Waluya, S. B. (2006). Persamaan diferensial. Yogyakarta: Graha Ilmu. 